\title{
The role of parents' learning facilitation mode in supporting informal learning in mathematics
}

\author{
I. Eloff*, J. G. Maree and L. H. Miller \\ University of Pretoria, South Africa
}

\begin{abstract}
*Corresponding author. Department of Educational Psychology, Faculty of Education, University of Pretoria, Pretoria 0002, South Africa. Email: irma.eloff@up.ac.za
\end{abstract}

The aim of this research was to investigate the way in which parents of Grade One learners in a traditionally black school facilitate learning to help their children acquire mathematical skills and knowledge in mathematics, and also to help them become confidently involved in and give meaning to mathematics learning in Grade One. A questionnaire, which was compiled after an intensive literature study, was administered and semi-structured interviews were held. Data were analysed quantitatively and qualitatively, and it became evident that the parents of Grade One learners in the school used for the investigation not only use dialogue to guide their children with regard to the demands of mathematics in Grade One, but they also rely on example as basic learning facilitation mode. The parents who guide their children informally with regard to mathematics in Grade One, however, most frequently use dialogue.

\section{Introduction}

The Third International Mathematics and Science Study Repeat Survey of the worldwide trends in respect of scholastic performance in mathematics and physical science confirmed that South African mathematics learners' performance was significantly poorer than the vast majority of other participating countries in tests that measured basic mathematical skills (Howie, 2001, p. 18). South Africa even 
fared significantly worse than the other two African countries that had participated in the survey, namely Morocco and Tunisia. South African learners struggled especially to deal with problems involving language. In general, learners experienced many problems communicating their answers in the language of the test (English) and they revealed that they did not have the basic mathematical knowledge that is required.

South Africa has been in a process of transformation in recent years. This transformation process has also impacted on the educational system (Cockburn, 1997, p. 4). There is a move towards outcomes-based education and, along with that, a further emphasis on not only the knowledge base of learners, but also on the skills acquired through the processes of learning. According to the Outcomes-Based Assessment paradigm, learners are expected to acquire skills that will prepare them for life in general, and especially in a workplace.

In conjunction with the move to an outcomes-based assessment approach in South African classrooms, the approach to mathematical learning and teaching in South Africa has changed considerably in recent years. The new curriculum, Curriculum 2005, promotes a problem-centred, outcomes-based approach to mathematics instruction (based on constructivist viewpoints).

An important implication of the move towards outcomes-based education is a stronger focus on the role of parents in facilitating informal learning in mathematics. The partnership between parents and teachers emphasises two important aspects of the role of the parents: preparation for learning and the creation of a willingness to learn in the learner (Van Wyk, 1996, p. 3; Winkler, 1998, p. 23). Parents not only influence a child's attitude towards learning; they also play an important role, particularly in relation to performance in mathematics in the primary school (Snyman, 1991, p. 1). Maree (1992, p. 110) indicates that the role of parents relates to the conscious or unconscious goal of creating confidence in the child, in order to give relevant meaning to the mathematical contents that he/she will encounter at school.

For those who work with young children, it is crucial to know that early childhood is the period when young children actively engage in acquiring concepts and learn fundamental process skills that form a basis for mathematical understanding (Charlesworth \& Lind, 2003, p. 2). Mathematics skills and concepts are ideally already acquired when children engage spontaneously in activities at a very young age. These activities involve playing with blocks, playing, cooking and taking part in outdoor activities. Young children who are exposed to such activities are provided with the opportunity to experience mathematical activities in their natural environment, and this lays the foundation of, and understanding and interest in, future learning (Earlychildhood, 2004, p. 4). The education of young learners deserves the attention and support of everyone responsible for education, including parents (Cooney, 2002, p. 1 ), especially since 'the basic quality of our emotional maturity' depends largely on the parent-child relationship (Trapp, 2004, p. 3), and this factor correlates positively with achievement in mathematics (Maree, 1992). 


\section{(Social) constructivism}

Currently the constructivist approach (and the work of authors such as Steffe et al., 1988; Ernest, 1989; Jaworski, 1989 - who expanded on the work of Piaget) is receiving a great deal of attention. According to this approach, 'knowledge is acquired, and cannot be given or transferred' In other words, no textbook or teacher can convey knowledge to a child—he/she has to create it for himself/herself. Apart from the fact that acquiring the ability to solve problems is a good reason to study mathematics, it also provides a context in which mathematics can be learned and practised. The focus thus shifts:

- from the child as someone who can do, to the child as someone who can think actively;

- from concepts and skills, to concepts, skills and processes;

- from mastering algorithmic skills, to developing algorithmic thinking; and

- from the application of mathematics to solving problems, to problem-solving as a method to investigate (Adler, 1992, p. 28).

This approach emphasises, inter alia, the importance of social interaction, working together in groups, problem-solving, an enquiring mind and the involvement of learners in classroom activities (Volmink, 1990). In other words, the discovery or creation of new mathematics is not seen merely as a logical, deductive activity. Discussion is an inevitable component of learning, as are the negotiation of meanings, quasi-empirical criticism and testing, logical argument and opportunities to develop independently in the construction of new mathematics (Lakatos, cited in Maree, 1992).

According to Murray et al. (1993, pp. 73-74), children build their own mathematical knowledge structures, regardless of the way mathematics is taught in the classroom. The learner is thus perceived as taking an active part in acquiring his/her own knowledge structure in mathematics.

Steffe and Kieren (1994, p. 21) contend that the following two key concepts in the constructivist approach have developed from the publications of Richards and Von Glaserfeld:

- Firstly, an individual constructs his/her own reality via actions and reflections on actions

- Secondly, reality is not being studied, but rather the construction of meaning.

This approach is also referred to by the Open University Course as Developing Mathematical Thinking Gordon (1989, p. 5) describes this programme as follows:

An important principle of the Open University programme is that pupils are introduced to mathematical language via their everyday activities and spoken language. In other words, pupils are introduced to abstract mathematical symbolism by talking about the concrete representations of those relationships, first with the instances they are familiar with and then with aids, structured to illustrate mathematical relationships.

The importance of the role played by the environment (including parental involvement) in the process of knowledge acquisition or learning during the early years is 
shown by Piaget (1973, p. 703), who states that knowledge and intelligence neither originate in the learner nor in the environment, but rather by interaction between the two.

Dienes has emerged as one of the notable constructivist mathematical psychologists in modern mathematics teaching and learning. He experimented both extensively and intensively in developing systems of learning through which the child manipulates objects in order to develop concepts and understand them (Molepo, 1997, p. 6). According to Mokhaba (1993, p. 132), Dienes 'regards the learning of a concept as a creative art which cannot be explained by any stimulus-response theory such as proposed by Gagné's stages of learning theory'.

His theory emphasises the use of objects and games in the teaching of mathematics. He believes in the active engagement of the learner in the process of the learning programme by playing with objects and playing games that have been systematically provided and arranged by the teacher to ensure an intuitive learning outcome.

His theory is divided into six different stages of participation in the teaching/ learning procedure in mathematics, as Bell (1978, pp. 123-128) postulates them:

1. Free play.

2. Games.

3. Searching for commonalities.

4. Representation.

5. Symbolisation.

6. Formalisation

These stages are briefly described in the following.

\section{Free play}

During this stage the learning activities do not have any systematic pattern. Learners are just engaged in the manipulation of such activities. The learner conducts experiments and he/she discovers various elements of concepts that have to be learned.

Rey and Post (1973, p. 40) state that during this stage the learner 'interacts directly with physical materials within the environment. Different embodiments provide exposure to the same basic concepts, but at this stage commonalities are observed'. According to Mokhaba (1993, p. 134), at this stage 'learners form mental structures and attitudes which prepare them to understand the mathematical structure of the concept.'

\section{Games}

After going through the free-play stage, learners start to realise that there are patterns and rules that govern certain events Such rules and patterns are followed in activities focused on games. Bell $(1987$, p. 25) shows how important games are in the teaching and learning of mathematics: 
Games permit students to experiment with the parameters and variations within the concept and to begin analysing the mathematical structure of the concept. Various games with different representations of the concept will help students discover the logical and mathematical elements of the concept.

\section{Searching for commonalities}

The importance of this stage is that learners look for common properties in concepts The games help them to trace these properties and their applications. These properties become a valuable mechanism for sorting (e.g. sets); classification (e.g; geometric figures) and contrasting (as in Bruner's theory of contrast and variation).

\section{Representation}

The need for the representation of the concept arises once the learners have managed to trace commonalities. The teacher may provide such a representation. Such a representation may include, inter alia, 'a diagram, a verbal representation or an example', according to Mokhaba (1993, p. 135).

\section{Symbolisation}

Verbal and mathematical symbols become necessary once the learners are able to make representations of concepts derived from the games. Learners should be encouraged to make their own symbols to represent their ideas before correct symbols are made available or accessible to the learners.

\section{Formalisation}

This is the final and advanced stage in the learning of mathematical concepts. It is the stage where proofs, refutations and axioms in mathematics can be formulated. Application of properties and commonalities acquired can now be effected through construction and analysis, to name but a few.

A combination of the various stages and aspects of learning described here will be a sensible basis necessary in the teaching of mathematics. Such a combination approach constitutes the constructivist approach. This approach is characterised by predominant involvement of the learner in the manipulation of learning opportunities made available by the teacher in or outside the classroom The teacher offers the necessary support and challenges.

The guidelines for mathematics and science used by National Association for Early Childhood in the USA emphasise the fact that mathematics begins with the handling and exploration of materials such as construction blocks, manipulative materials, toys and tools, as well as observation and classification of environmental changes (Maclellan, 2001, p. 74; Charlesworth \& Lind, 2003, p. 1; Pound, 2003, p. 6). Pound (2003, pp. 6-13) emphasises the fact that the experiences on which 
young children's learning is based continue to be important, but over time some more overtly mathematical experiences will and must be added. Between the ages of five and seven years children are more comfortable with, and ready to represent, ideas and objects through a variety of media as well as symbols.

The development of early mathematical concepts and skills forms part of the South African school curriculum for Grade R learners (Department of Education, 2002). Educators do not always devote enough time and planning to the development of mathematical processes, knowledge and strategies for these young learners, which can result in young learners not acquiring fundamental concepts regarding the understanding of early mathematics.

\section{The implications of learning theories for early learning in mathematics}

The following implications may be of relevance to the current research:

- The mathematical knowledge offered to children should go hand in hand with their developmental process and epistemological development.

- The background in mathematics of children should be the starting point of abstract concept development.

- The tradition and culture of children may be fully explored to discover the unrecognised and subtle mathematical wealth as a basis for the discovery and formalisation exercises in learning.

- All learning theories may be conjunctively and collectively harnessed to develop into situations of mathematical learning that will encourage insightful understanding of concepts.

- Parents have a major role to play in facilitating their children's acquisition of mathematical skills, particularly during children's early (preschool) years.

Traditional learning theories do not make adequate provision for the social and educational context of learning. The important role of environmental influences, emotional factors and language in facilitating the child's cognitive development is often understated.

\section{Parents' learning facilitation mode in facilitating the acquisition of early mathematics}

To expand our knowledge of the role of the parents in the aforementioned regard, it is necessary to investigate the nature of their interaction with and support for their children when they are facilitating learning. The purpose of the current research was to investigate and explore the basic learning facilitation modes parents of Grade One learners in a traditionally black ${ }^{1}$ school in South Africa utilise to prepare their children for the demands of mathematics in Grade One, thereby facilitating their informal learning processes. The ideal was to focus on the method or primary learning facilitation mode the parents utilised in order to introduce their children to mathematical concepts. Traditionally four major learning 
facilitation methods were distinguished: dialogue, example, instruction and play (Snyman \& Kühn, 1993, p. 38). The assumption in this research was that parents can be supported to enhance mathematical knowledge and skills in their children, once the ways in which they are already supporting their children can be explored and comprehended.

\section{Research design}

Two complementary approaches, qualitative and (semi-)quantitative, were implemented. The research reported here was not a quantitative comparative study conducted with two groups of subjects, but a study over an extended period of time with parents in a traditionally black school.

The study draws on the theoretical notions outlined in this article to assist in an understanding of the construction by parents of their role in facilitating learning in mathematics. The intention or purpose is to expand knowledge regarding the role of parents in learning facilitation in mathematics and to determine the narratives that they draw on to assist their children, and not to generate universal laws concerning how parents facilitate learning in mathematics.

\section{Research questions}

The research process was guided by the following questions:

- What are the primary ways of facilitating learning that parents of Grade One learners in a traditionally black school in South Africa use?

- What are the primary subcategories of the primary method and their frequency, as utilised by parents?

\section{Participants}

The study took place at Masingita Primary School in the Pretoria area. Eight families were randomly selected from a class list containing the names of all families of Grade One learners. The purpose and procedures of the research were explained to the headmaster and the Grade One teacher, after which letters were sent to parents of Grade One learners, inviting them to participate in the research. Participants were ensured of anonymity and confidentiality of participation and the specific nature of the interview was explained.

The participants were black females living in a traditionally black area in South Africa. They were the mothers of Grade One learners. Variables such as age, religion and language were not taken into account. Most of the participants were not married ( $n$ = 7), but one-half of them were living with the father of the child. The other half were staying with the maternal grandparents of the child. There was a high incidence of unemployment and single parenthood among the participants. The participants also had limited scholastic experience of mathematics. Furthermore, the number of 
people sharing residence with the parent and the child varied considerably, ranging from 4 to 10 people.

\section{Schedule}

Appointments were scheduled on weekdays, during which semistructured interviews were conducted with the parents according to a questionnaire, which had been compiled after an intensive literature study in respect of both the role of discussion in mathematics and the mathematical skills that had to be acquired in Grade One. The questionnaire was designed to cover the relevant topics relating to the central research question. Due to language difficulties a translator was also present at the interviews. The interviews were conducted in English at the school during school hours. The interviews were recorded by means of an audiocassette and note-taking during and after the interview.

\section{Data collection and analysis}

After the interviews, qualitative and quantitative data analysis took place. The results were quantified to gain clarity in terms of frequencies. Various significant themes from the interviews were then identified, divided into themes and subthemes, and qualitatively explored to enrich the data further.

The parents were observed during various sessions. Subsequently, semi-structured, individual, in-depth interviews were conducted with the parents to determine the primary ways in which they facilitated learning, as well as to determine the primary subcategories of the primary method and their frequency, as utilized by parents.

The data were analysed and themes that emerged were subsequently triangulated with the findings of a literature study. Conversations were taped and analysed on the basis of Morse and Field's approach (comprehending, synthesising, theorising and recontextualising) (Morse, 1994; Morse \& Field, 1996).

\section{Ensuring trustworthiness}

Trustworthiness (Guba, cited in Schurink et al., 1998, p. 331) of the results was facilitated in the following way. Much time was spent with participants during the course of the research, which facilitated rapport and helped the parents feel at ease. Qualitative researchers with many years' experience in interviewing conducted the interviews in an attempt to eliminate bias. The lecturers were both highly trained and vastly experienced, not only in teaching mathematics at primary and secondary level, but also in the implementation of anti-bias programmes. Trustworthiness was further enhanced by peer examination (researchers reviewed each other's work at all stages), independent coding and comparison of information at different stages of the research. The relationship of trust between the lecturers and the parents and the fact that parents were motivated to contribute to the investigation further facilitated trustworthiness. 


\section{Ethical measures}

Permission was requested and obtained in writing from the education departments as well as from the parents to conduct the research and publish the findings. The assurance was given that no individual would be identified.

\section{Limitations of the study}

The sample was relatively small due to the fact that only eight parents responded. The study was thus limited in scope and this fact limits the potential for inference. Furthermore, standardised questionnaires were not used and it is possible that the results could be interpreted differently by another researcher. Finally, paternal involvement may have influenced the results, and language-related problems were experienced (the majority of respondents could not speak English and the services of an interpreter had to be acquired).

\section{Results}

A distinction was drawn between the quantitative data and the qualitative data. After careful analysis the results were integrated.

\section{Quantitative data}

The results of this research indicate that an educationally significant percentage of the parents of Grade One learners in this school primarily utilise dialogue (49.0\%) as a method of facilitating learning and of preparing their children for the demands of mathematics in Grade One. However, it is also evident that an educationally significant percentage of the sample makes use of example (32.7\%) as a learning facilitation method. Graphic representation of this data (Figure 1) shows that the two primary methods seem to be dialogue and example, whereas the frequency of play (6.1\%) and instruction (12.2\%) seem to indicate under-utilisation of these particular methods-specifically in terms of their use for facilitating their children's acquisition of mathematical concepts.

Furthermore the results also indicate a difference in the frequency of the use of the various subcategories of dialogue, namely 'questioning and answering', 'explanation' and 'telling'. An analysis of Figure 2 indicates that the subcategory 'questioning and answering' is most frequently used, whereas 'telling' is least used in this regard.

\section{Qualitative data}

The quality and exact nature of dialogue at home regarding children's acquisition of informal mathematical skills were further investigated on the basis of the results of semi-structured interviews. The theme 'dialogue' emerged as the most significant one in this research. This theme was thus further analysed in terms of subthemes; namely, 


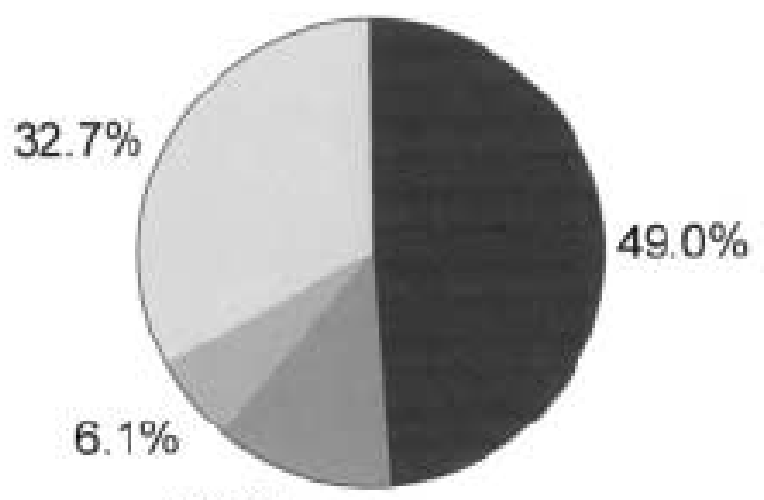

$12.2 \%$

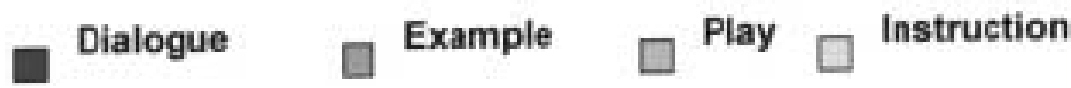

Figure 1. Frequency of the use of learning facilitation methods

questions and answers, explaining and telling. These subthemes were subsequently further explicated by means of examples that were mentioned by participants. The themes were then related to particular mathematical concepts, skills and knowledge.

Theme 1: dialogue. Careful analysis of the qualitative data yielded the following subthemes:

Subtheme 1: question and answer. An analysis of the interviews shows that six participants utilised questioning and answering to explore mathematical concepts and skills such as classification, spatial orientation, time concepts, fractions, counting, volume and colours.

Examples:

- Asking a child to sort washing according to colours.

- Asking a child with which foot he/she kicks a ball.

- Asking the child to tell time on a digital clock.

- Asking a child to cut an apple in half.

- Asking a child to count balls.

- Asking a child to fetch half a glass of water.

- Asking a child to point at colours in a magazine. 


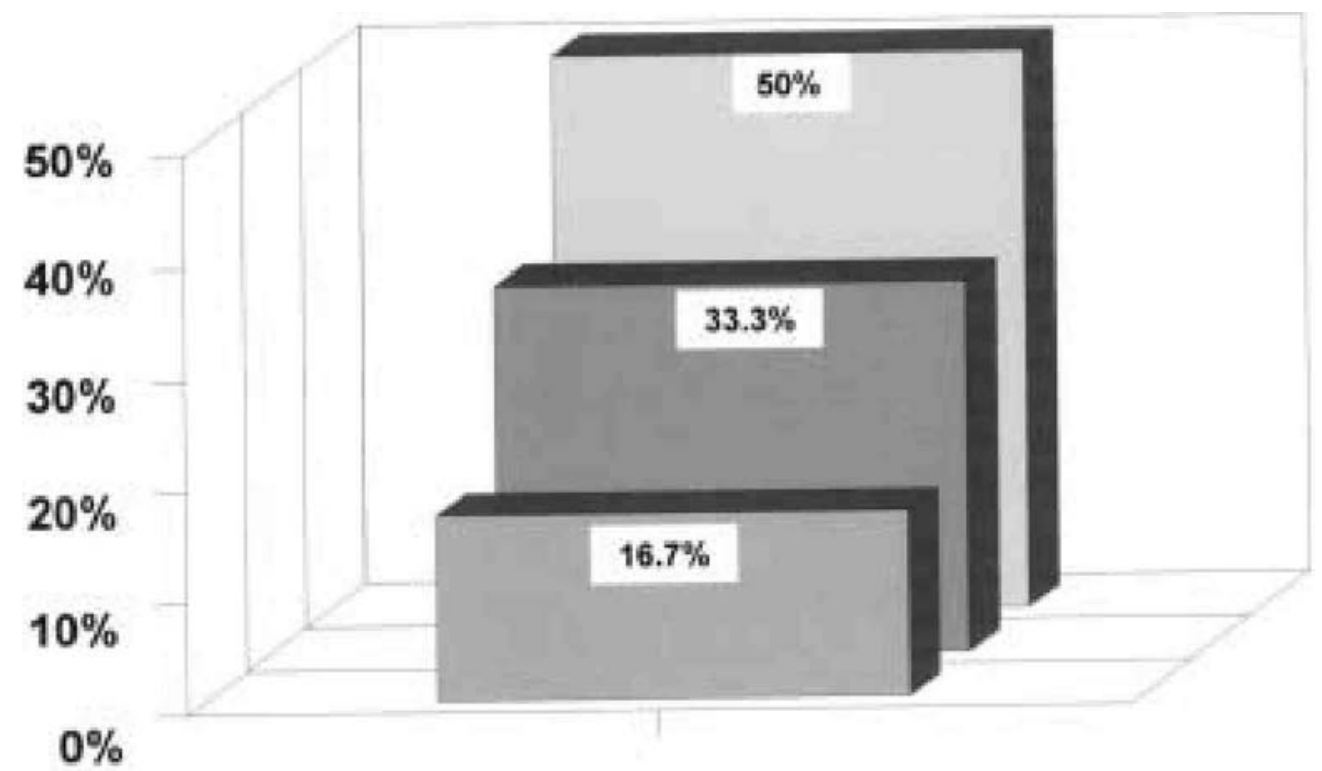

Question and answer

Explaining

Telling

Figure 2. Frequency of the use of the categories of dialogue used

Subtheme 2: explaining. Three participants indicated that they had made use of explanation as part of their informal support for the learners. It was used to support skills and knowledge in terms of counting, time concepts, volumes, fractions and monetary values.

Examples:

- Using paper to demonstrate counting from 1 to 10.

- Explaining counting by means of sticks and sweets.

- Explaining time on the clock on the wall.

- Explaining volume by means of drinking glasses with water.

- Explaining that half a cake is less than a whole cake.

- Explaining the costs of household items.

Subtheme 3: telling. Four participants indicated that they use telling as a part of their informal support. This was used for the mathematical skills and knowledge of colours, shapes and monetary values.

Examples: 
- Telling a child what a particular colour is.

- Telling a child what a particular shape is.

- Telling a child what money to use to buy an item from the store.

Theme 2: instruction. Five participants indicated that they use instruction to support the informal mathematical learning of their Grade One children. This was used for the mathematical skills and knowledge of colours, counting and monetary values.

Examples:

- Instructing a child to write down numbers 1 to 10.

- Instructing a child to wear a white shirt.

- Instructing a child to buy bread without explaining.

Theme 3: play. Three participants indicated that they use play as a part of their informal support for mathematics. The games that were used were card games and 'kick the tin' Examples:

- Using the numbers on cards to play a game-for instance, winning with three evennumber cards.

- Running with a tin while counting. If the child does not count fast enough they have to throw the tin against another tin.

Theme 4: example. Six participants indicated that they utilise example as part of their informal support for the development of mathematical knowledge and skills in their children. This was used for the skills of counting, number recognition, fractions and volumes. Examples:

- Using the scores at a soccer match as an example of the concepts of more and less.

- Showing that one sweet is equal to one stick.

- Showing the numbers on the shirts of soccer players as examples of numbers.

- Showing that cutting a piece of bread in two results in two halves.

- Showing that smaller children drink less cool drink from a glass.

\section{Discussion}

Our findings support the views expressed by Slavin (1994, p. 77); namely, that parental behaviours that encourage 'oral language development' inform many of the psychological-educational implications that are derived from young children's language development.

Analysis of both the quantitative and the qualitative data indicates data indicates that the parents in the current research group rely strongly on dialogue as a primary learning facilitation mode, when supporting their Grade One children in the 
development of their informal mathematical skills and knowledge. Dialogue is used during approximately one-half of the time that parents spend on facilitating mathematical learning. Although less frequently used, the use of an example is also presented as a favoured mode of learning facilitation.

This phenomenon has at least two implications. On the one hand it means that parents could expand upon these learning facilitation modes, as they were already utilising these modes in a spontaneous, natural way. On the other hand it also means that more variety could be 'imported' into their informal support with the utilisation of the other two modes of instruction and facilitation of mathematical learning. Play in particular has been shown to be of great benefit to learners, specifically during the early years (Johnson et al., 1999), whereas, in this group of participants, this learning facilitation mode was under-utilised. However, all children are not alike; and in the same way that they vary in terms of age, sex, family background and social surroundings, they differ with respect to the characteristic ways in which they learn and think Parents and teachers should be trained and assisted to become versatile with regard to the basic mode of instruction or learning facilitation, taking into account both the characteristic way of learning of the particular child and the developmental level of the child. Furthermore the partnership between parents and schools needs to be encouraged and strengthened at all times, since research has shown that 'children whose parents are actively involved in their schooling achieve better than those whose parents are less involved' (Epstein \& Scott-Jones, cited in Slavin, 1994, p. 79).

Taking cognizance of the potential overlaps between learning facilitation modes, it seems that balanced utilisation of all four basic learning facilitation modes should prove to be the most effective approach in supporting early (informal) mathematical learning, especially in the light of the developmental level of Grade One learners. Dialogue is an important part of their learning processes, but the same holds true for play, instruction and example.

Knowledge is constantly in a process of transformation and construction. This necessitates the creation of self-awareness by focusing on the processes of discovery and exploration as well as on the products created by this process. Parents of Grade One learners play an important role in this developmental process. Parents and children should be learning together and both become educator-learners. Parents are not fountains of knowledge, 'pouring into' their children all the knowledge that they need. They should be asking questions, playing, instructing and pointing to examples with their children, thereby sharing the responsibility for the learning process.

The current research has other implications for the classroom and the Grade One classroom educator as well. The current finding that parents rely heavily on the learning facilitation modes of dialogue and example may also mean that the learning facilitation modes of play and instruction could be utilised more extensively by classroom educators, facilitating a balance between the use of these modes of learning facilitation. In Grade One, particularly, these two learning facilitation modes can be alternated successfully. The possibility of an integrated curriculum, which is necessitated by outcomes-based education, is further enhanced by this approach. 
The approach to mathematical learning and teaching in South Africa has changed considerably in recent years. A new nationwide curriculum, Curriculum 2005, which promotes a problem-centred, outcomes-based approach to mathematics instruction (based on constructivist viewpoints), has been introduced in Grade One since 1997, promoting learning through learners' own experiences, and less formal teaching and assessment, with the focus on outcomes-based assessment. The pedagogy promoted by Curriculum 2005 encourages cooperation between parents and teachers, and stimulates parental involvement that includes educating the parents in the new approach to teaching mathematics. Satisfactory cooperation between teachers and parents can be a major asset to improve children's achievement in mathematics.

Mechanisms with regard to which education by teachers should take place include facilitating learners' acquisition of the limited, technical language of mathematics. Furthermore, the learner must feel that mathematics problems are real and interesting enough to be worth solving, and plenty of time for solving the problem should be given.

Hopefully this article will contribute towards parental involvement in the prevention of mathematical problems experienced by the learner, especially in the Foundation Phase and ultimately also towards better achievement in mathematics throughout school.

Finally, it has become clear that Grade One teachers should be trained more adequately to provide guidance to parents regarding ways to help their children acquire (informal) mathematical skills and knowledge in Grade One. Parent-teacher conferences, for instance, should take place on a regular basis, and teachers should be prepared to listen carefully to what parents have to say (Woolfolk, 1993, p. 569). The focus should be on facilitating a partnership between schools and parents, with mutual benefits for both parties. The pre-primary years are, after all, of crucial importance in terms of equipping children to become mathematically literate and to enter school with an adequate knowledge of preschool mathematical skills. The facilitation of extensive parental guidance programmes to attain these ideals is strongly recommended. Teachers need to facilitate a 'collaborative environment' where they can share experiences with colleagues and mentors (Cooney, 2002, p. 20) as well as parents.

\section{Notes}

1. In spite of the fact that any classification by ethnic or population group is an artificial construct aimed at distinguishing between people, it is used in this paper for the purpose of drawing meaningful conclusions and pointing out the inequalities that have for so long existed along these lines in South Africa. The ultimate aim is to make recommendations to rectify the situation.

2. The authors should like to thank the parents and teachers who participated in this research project and gave them permission to use it. 


\section{References}

Adler, J. (1992) What is new and different in the draft core syllabus for mathematics: Std 2-4?, Pythagoras, 28, 23-26.

Bell, F. H. (1978) Teaching and learning mathematics (Dubuque, IA, W. M. C. Brown Company).

Bell, A. (1987) The small rural primary school-a matter of quality (London, Falmer Press).

Charlesworth, R. \& Lind, K. K. (2003) Math and science for young children (4th edn) (London, Delmar).

Cockburn, P. (1997) Building a brighter future curiculum 2005 (Pretoria, CTP Book Printers).

Cooney, T. J. (2002) Mathematics teacher education in rural communities: developing a foundation for action, paper presented at the ACCLAIM Research Symposium, Ravenwood Castle, McArthur, Ohio. Available online at: http://acclaim. coe.ohiou.edu/ (accessed 2 June 2004).

Department of Education (2002) Revised national curriculum statement Grades R-9 (schools): mathematics (Pretoria, Department of Education).

Earlychildhood (2004) Science in the early childhood classroom: developing and acquiring fundamental concepts and skills. Available online at: http://www.earlychildhood.com/Articles/ index . cfm?A $=256 \&$ FuseAction=Article (accessed 1 June 2004).

Ernest, P. (Ed.) (1989) Mathematics teaching: the state of the art (London, Palmer Press).

Gordon, A. (1989) The maths centre for primary teachers. Its impact on Sowveto teachers and their learners (Pretoria, Human Sciences Research Council).

Howie, S. (2001) Mathematics and science performance in Grade 8 in South Africa 1998/9 (Pretoria, Human Sciences Research Council).

Jaworski, B. (1989) Is versus seeing as, in: D. Pimm (Ed.) Mathematics, teachers and children (London, Open University with Hodder and Stoughton).

Johnson, J. E., Christie, J. F. \& Yawkey, T. D. (1999) Play and early childhood development (New York, Longman).

Maree, J. G. (1992) The design of a model for the identification and handling of inadequate achievement in mathematics. Unpublished $\mathrm{Ph} . \mathrm{D}$. thesis, University of Pretoria.

Maclellan, E. (2001) Representing addition and subtraction: learning the formal conventions, European Early Childhood Education Research fournal, 9(1), 73-86.

Mokhaba, M. B. (1993) The application of the activity principle in mathematics teaching - a strategy for teacher training. Unpublished Ph.D. thesis, University of South Africa.

Molepo, J. M. (1997) The role of mathematics in developing rural and tribal communities in South Africa. Unpublished Ph.D. thesis, University of Pretoria.

Morse, J. M. (1994) Emerging from the data: the cognitive processes of analysis in qualitative inquiry, in: J. M. Morse (Ed.) Critical issues in qualitative research methods (Thousand Oaks, CA, Sage).

Morse, J. M. \& Field, P. A. (1996) Nursing research: the application of qualitative approaches (London, Chapman \& Hall).

Murray, H., Olivier, A. \& Human, P. (1993) Voluntary interaction groups for problem-centred learning, in: I. Hirabayashi, N. Nohda, K. Shigematsu \& F. Lin (Eds) Proceedings of the Seventeenth International Conference for the Psychology of Mathematics Education (vol. II) (Tsukuba, Japan).

Piaget, J. (1973) Main trends in inter-disciplinary research (London, Allen \& Unwin).

Pound, L. (2003) Supporting mathematical development in the early years (Buckingham, Open University Press).

Rey, R. E. \& Post, T. R. (1973) The mathematics laboratory: theory to practice (Boston, MA, Prindle, Weber and Schmidt).

Schurink, W. J., Schurink, E. M. \& Poggenpoel, M. (1998) Focus group interviewing and audiovisual methodology in qualitative research, in: A. S. De Vos (Ed.) Research at grassroots: a primer for the caring professions (Pretoria, J. L. van Schaik), 313-333.

Slavin, R. E. (1994) Educational psychology. Theory and practice (London, Allyn \& Bacon).

Snyman, A. (1991) A metacognitive perspective on the disharmonic learning facilitation dynamics in reception year mathematics. Unpublished M.Ed. dissertation, University of Pretoria.

Snyman, R. \& Kühn, M. J. (1993) Structured instruction and learning, in: W. J. Louw (Ed.) Classroom practice (Pretoria, Academica), 36-45. 
Steffe, L. P. \& Kieren, T. (1994) Radical constructivism and mathematics education, foumal for Research in Mathematics Education, 25(6), 711-733.

Steffe, L. P., Cobb, P. \& Von Glaserfeldt, E. (1988) Construction of arithmetical meanings and strategies (New York, Springer-Verlag).

Trapp, Y. U. (2004) Multiple intelligences: the learning process in our students. Available online at: http://www.yale.edu/ynhti/curriculum/units/2001/6/01.06.10.x.html (accessed 1 June 2004).

Van Wyk, E. R. (1996) The pre-school child and literacy experience. Unpublished M.Ed. dissertation, University of Pretoria.

Volmink, J. (1990) Towards a framework for curriculum change, in: Proceedings of the Maths, Science, Technology Curriculum Centre Conference (Johannesburg, Science Education Project).

Winkler, G. (1998) All children can learn (Cape Town, Francolin Publishers).

Woolfolk, A. E. (1993) Educational psychology (Boston, MA, Allyn \& Bacon). 